\title{
Beta carbonic anhydrases: novel targets for pesticides and anti-parasitic agents in agriculture and livestock husbandry
}

Reza Zolfaghari Emameh ${ }^{1,2,3^{*}}$, Harlan Barker ${ }^{1,2}$, Vesa P Hytönen ${ }^{2,3}$, Martti E E Tolvanen ${ }^{4,2}$ and Seppo Parkkila ${ }^{1,2,3}$

\begin{abstract}
Background: The genomes of many insect and parasite species contain beta carbonic anhydrase ( $\beta-C A)$ protein coding sequences. The lack of $\beta$-CA proteins in mammals makes them interesting target proteins for inhibition in treatment of some infectious diseases and pests. Many insects and parasites represent important pests for agriculture and cause enormous economic damage worldwide. Meanwhile, pollution of the environment by old pesticides, emergence of strains resistant to them, and their off-target effects are major challenges for agriculture and society.

Methods: In this study, we analyzed a multiple sequence alignment of $31 \beta$-CAs from insects, some parasites, and selected plant species relevant to agriculture and livestock husbandry. Using bioinformatics tools a phylogenetic tree was generated and the subcellular localizations and antigenic sites of each protein were predicted. Structural models for $\beta$-CAs of Ancylostoma caninum, Ascaris suum, Trichinella spiralis, and Entamoeba histolytica, were built using Pisum sativum and Mycobacterium tuberculosis $\beta$-CAs as templates.

Results: Six $\beta$-CAs of insects and parasites and six $\beta$-CAs of plants are predicted to be mitochondrial and chloroplastic, respectively, and thus may be involved in important metabolic functions. All 31 sequences showed the presence of the highly conserved $\beta$-CA active site sequence motifs, CXDXR and HXXC (C: cysteine, D: aspartic acid, R: arginine, $\mathrm{H}$ : histidine, $\mathrm{X}$ : any residue). We discovered that these two motifs are more antigenic than others. Homology models suggested that these motifs are mostly buried and thus not well accessible for recognition by antibodies.

Conclusions: The predicted mitochondrial localization of several $\beta$-CAs and hidden antigenic epitopes within the protein molecule, suggest that they may not be considered major targets for vaccines. Instead, they are promising candidate enzymes for small-molecule inhibitors which can easily penetrate the cell membrane. Based on current knowledge, we conclude that $\beta$-CAs are potential targets for development of small molecule pesticides or anti-parasitic agents with minimal side effects on vertebrates.
\end{abstract}

Keywords: Beta carbonic anhydrase, Inhibitors, Insecticides, Pesticides, Anti-parasitic agents, Agriculture, Livestock husbandry

\section{Background}

Various pests, including weeds, insects, and plant viruses, often reduce crop production by $25-50 \%$ [1,2]. On the other hand, the widespread use of synthetic insecticides for controlling pests produces many negative consequences (e.g. insecticide resistance, toxicity to mammals and other non-target animals, residue problems, and

\footnotetext{
* Correspondence: reza.zolfaghari.emameh@uta.fi

${ }^{1}$ School of Medicine, University of Tampere, 33520 Tampere, Finland

${ }^{2}$ BioMediTech, University of Tampere, 33520 Tampere, Finland

Full list of author information is available at the end of the article
}

environmental pollution). High risk groups exposed to pesticides include: production workers, formulators, sprayers, mixers, loaders, and agricultural farm workers. Residual pesticides represent a real threat for human health. When 9700 samples of fruits and vegetables were analyzed for seven pesticides (Acephate, Chlopyriphos, Chlopyriphos-methyl, Methamidophos, Iprodione, Procymidone, and Chlorothalonil), $5.2 \%$ of the samples were found to contain residues. Pesticides can contaminate soil, water, and turf. In addition to killing insects or weeds, pesticides can be toxic to other organisms including birds, 
fish, beneficial insects, and non-target plants [3]. The extensive use of pesticides, such as Dichlorodiphenyltrichloroethane (DDT), in recent decades has led to their recurrent detection in many surface and ground waters [4]. As a result of these negative consequences, natural products have become popular among consumers [5].

As of the 1960s pesticide resistance had already evolved in some key greenhouse pests, prompting the development of alternative methods of management. The pressure to reduce insecticide usage was reinforced by the adoption of bumble-bees for pollination within greenhouses [6]. Biological control plays a central role in the production of many greenhouse crops. The term "Biopesticide" encompasses a broad array of microbial pesticides, including biochemicals derived from micro-organisms and other natural sources, and those resulting from the incorporation of DNA into various agricultural commodities [7]. Bacteria, fungi, viruses, entomopathogenic nematodes (ENPs), and herbal essential oils are often used as biopesticides [8]. Novel approaches to control pests involve targeting of specific insect and parasite enzymes. This can be done using either chemical or biological compounds. Acetylcholinesterase (AChE) of the malaria mosquito (Anopheles gambiae) has been reported as a target site for pesticides [9]. Three pesticides, Atrazine, DDT, and Chlorpyrifos, have been determined to affect the esterase (GE), glutathione S-transferase (GST), cytochrome P450 monooxygenase (P450), and acetylcholinesterase (AChE) activities of Chironomus tentans (an aquatic midge) [4]. Proteinases serving as insect digestive enzymes are defined targets in pest control [10]. Enzyme inhibitors, such as: piperonyl butoxide (PB), a mixed-function oxidase (MFO) inhibitor; triphenyl phosphate (TPP), a carboxyesterase (CarE) inhibitor; and diethyl maleate (DEM), a glutathione S-transferase (GST) inhibitor, have been used to inhibit insect enzymes [11]. Inhibition of Plasmodium falciparum carbonic anhydrase (CA) with aromatic heterocyclic sulfonamides was investigated in 2011 [12]. In another study, a thiabendazole sulfonamide showed a potent inhibitory activity against both mammalian and nematode $\alpha$-CAs [13].

Five independently evolved classes of CAs $(\alpha, \beta, \gamma, \delta$, and $\zeta$ ) have been identified, of which one or more are found in nearly every cell type, underscoring the general importance of this ubiquitous enzyme in nature [14]. The CAs are involved in several important biological processes, such as respiration and transportation of $\mathrm{CO}_{2}$ and bicarbonate between metabolizing tissues, $\mathrm{pH}$ and $\mathrm{CO}_{2}$ homeostasis, electrolyte secretion in different organs, bone resorption, calcification, tumorigenicity, and some biosynthetic reactions including gluconeogenesis, lipogenesis, and ureagenesis [15]. Since 1990, many demonstrated and putative $\beta$-CAs have been discovered not only in photosynthetic organisms, but also in eubacteria, yeast, archaeal species [16] and 18 metazoan species [17]. Recently, we reported $52 \beta$-CAs in metazoan and protozoan species [18]. At least one study has shown the effects of $\beta$-CA inhibitors as anti-infective agents on different bacterial and fungal pathogens [19], yet this approach has not been tested in vivo in metazoans or protozoans. In this article, we introduce $\beta$-CAs as novel potential target enzymes to control agricultural and veterinary insects and parasites which cause enormous economic losses worldwide.

\section{Methods}

\section{Identification of putative $\beta$-CA enzymes and multiple se-} quence alignment (MSA)

In total, 23 parasite and 8 plant $\beta$-CA sequences relevant to agriculture and livestock husbandry, or as model organisms, and one bacterial sequence (Desulfosporosinus meridiei) were retrieved from UniProt (http://www.uniprot. org/) and NCBI (http://www.ncbi.nlm.nih.gov/). The full list of agriculture and livestock husbandry pests and plants containing $\beta$-CA addressed in this research are shown in Table 1 . We focused on 98 amino acid residues around the catalytic active site of all tested $\beta$-CAs, starting 7 amino acid residues prior to the first highly conserved sequence (CXDXR). The Clustal Omega algorithm [20] within the Jalview program (version 2.8.ob1) (http://www. jalview.org/) was used to create a multiple sequence alignment (MSA) [21].

\section{Phylogenetic analysis}

All sequences were individually analyzed for completeness and quality. The $\beta-\mathrm{CA}$ sequence for Solenopsis invicta (UniProt ID: E9IP13) was determined to have a spurious exon when the genomic sequence was analyzed by the Exonerate program using the other $\beta$-CA proteins as query sequences, and subsequently 17 amino acids were removed [49]. Similarly, the full genome of Acyrthosiphon pisum was analyzed. Of the three Acyrthosiphon pisum $\beta$-CA sequences identified in UniProt, two were incomplete (UniProt IDs: C4WVD8 and J9JZY3) and found to be fragments of the same complete protein predicted in our analysis (Acyrthosiphon pisum BCA-2). Finally, the full genome of Ichthyophthirius multifiliis was scanned for $\beta$-CA proteins using the same method, and two new putative $\beta$-CA proteins were identified (Ichthyophthirius multifiliis BCA-3 and BCA-4).

A protein sequence alignment was created using Clustal Omega [20] based on which the corresponding nucleotide sequences were then codon-aligned by the Pal2Nal program [50]. Using the Desulfosporosinus meridiei bacterial sequence as an outgroup, a phylogenetic analysis was computed using Mr. Bayes v3.2 [51] with the GTR model of codon substitution and all other parameters set to default. In total, 200,000 generations were computed with a final standard deviation of split frequencies of $3.33 \times 10^{-4}$. 
Table 1 Agriculture and livestock husbandry pests, and plants containing $\beta$-CA which applied in this research

Species name
Ancyrthosiphon pisum
Ascaris suum (Ascaris
lumbricoides)
Caligus clemensi
Camponotus floridanus
Ceratitis capitata
Culex quinquefasciatus
Dendroctonus ponderosae
Entamoeba histolytica
Entamoeba nuttalli Entamoeba
dispar

Haemonchus contortus

Ichthyophthirius multifiliis

Lepeophtheirus salmonis

Necator americanus

Solenopsis invicta

Tribolium castaneum

Trichinella spiralis

Trichoplax adhaerens

Arabidopsis thaliana

Pisum sativum

Gossypium hirsutum

Nicotiana tabacum

Vitis vinifera

Solanum tuberosum

Populus trichocarpa

Capsella rubella

General name

pea aphid

A species of phylum Nematoda

large roundworm of pigs

Plural sea lice

Carpenter ant

Mediterranean fruit fly (Medfly)

Southern house mosquito

Mountain pine beetle (MPB)

A genus of phylum Amoebozoa

Trichostrongyloid nematode (Red stomach worm, wire worm or barber's pole worm)

Freshwater ich, or freshwater ick

Salmon louse

New World hookworm

Red imported fire ant (RIFA)

Red flour beetle

\section{Pork worm}

Adherent hairy plate

Mouse-ear cress

Pea

Upland cotton

Tobacco

Grape vine

Potato

Black cottonwood or California poplar

A genus from Mustard family
Sap-sucking in forage crops, such as peas, clover, alfalfa, and broad beans

Infection of the small intestine of dogs and human (zoonosis)

Ascariasis in pig and human (zoonosis)

Major ectoparasites of farmed and wild Atlantic salmon

Nest in live or dead trees, rotting logs and stumps, buildings, telephone poles, and other wooden structures

Causing extensive damage to a wide range of fruit crops

Vector of West Nile virus (WNV), St. Louis encephalitis virus and other arboviruses, lymphatic filariasis, Wuchereria bancrofti, and Plasmodium relictum (avian malaria)

Attacks to old or weakened trees, and speeds to younger forests

Causative agent of amoebiasis in animals and human (zoonosis)

Causative agent of Haemonchosis by

blood feeding through attachment to abomasal mucosa of ruminants

White spot disease in freshwater fishes and rarely in human (zoonosis)

Parasite living on wild salmon and fish farming

Necatoriasis in dog, cat, and human (zoonosis)

Mound-building activity, Damage plant roots which leads to loss of crops, and interfere with mechanical cultivation

Pest of stored grain products, carcinogenic by secretion of quinones, causative agent of occupational lgE-mediated allergy and some other diseases

Trichinosis in rat, pig, bear and human (zoonosis)

Adherence to the wall of a marine aquariums
Main concerns

Food canning industry [22]

Dog breeding [23]

Pig breeding [24]

Fishing and fish farming [25]

Wooden instrument industries and consumers [26]

Invasion to orchards [27]

Zoonotic diseases which affect both humans and animals health [28]

Wooden instrument industries and consumers [29]

Humans and animals health [30]

Sheep and goat farming [31]

Fish and fish farming [32]

Fish and fish farming [25]

Humans and animals health [33]

Wooden instrument industries and consumers, and gardening [34]

Wheat, flour, cereal and nut based food industries [35-38]

Pig breeding [39]

Aquarium and ornamental fishing industry [40]

A popular model organism in plant biology and genetics [41]

Pea is most commonly the small spherical seed or the seed-pod [42]

Upland cotton is the most widely planted species of cotton [43]

Its leaves are commercially processed into tobacco [44]

Commercial significance for wine and table grape production [45]

The world's fourth-largest food crop, following maize, wheat and rice [46]

A model organism in plant biology [47]

A member of Mustard family [48] 
The final phylogenetic tree was visualized in FigTree (http:// tree.bio.ed.ac.uk/software/figtree/).

\section{Prediction of subcellular localization}

Subcellular localization of each identified invertebrate $\beta$-CA was predicted using the TargetP webserver (http:// www.cbs.dtu.dk/services/TargetP/). TargetP is built from two layers of neural networks, where the first layer contains one dedicated network for each type of targeting sequences, such as cytoplasmic, mitochondrial, or secretory peptides, and the second layer is an integrating network that outputs the actual prediction $(\mathrm{CTP}=$ cytoplasmic, $\mathrm{mTP}=$ mitochondrial, $\mathrm{SP}=$ secretory, or other). It is able to discriminate between cTPs, mTPs, and SPs with sensitivities and specificities higher than what has been obtained with other available subcellular localization predictors [52].

\section{Prediction of antigenic sites in $\beta-C A$}

The protein sequences of 23 parasite and 8 plant $\beta$-CAs were analyzed with the European Molecular Biology Open Software Suite (EMBOSS) program Antigenic (http:// emboss.bioinformatics.nl/cgi-bin/emboss/antigenic). EMBOSS Antigenic predicts potentially antigenic regions of a protein sequence, using the method of Kolaskar and Tongaonkar [53]. Application of this method to a large number of proteins has shown that their accuracy is better than most of the known methods [54-56].

\section{Homology modelling}

Homology models of four selected $\beta$-CAs, including FC551456 (Ancylostoma caninum), F1LE18 (Ascaris suum), E5SH53 (Trichinella spiralis), and C4LXK3 (Entamoeba histolytica) were prepared by first selecting the most suitable template structure. For this purpose, a BLAST search of the PDB database (http://www.rcsb.org/pdb/ home/home.do) was performed using each of the four sequences. Results for three out of these four searches revealed that PDB structure 1EKJ ( $\beta$-CA from Pisum sativum) possessed the most similar sequence, while PDB id $2 \mathrm{~A} 5 \mathrm{~V}$ ( $\beta$-CA from Mycobacterium tuberculosis) was found to be the most similar to C4LXK3 (Entamoeba histolytica). Clustal Omega was used to prepare a multiple sequence alignment for those six sequences.

The multiple sequence alignment showed nine completely conserved residues within the sequences; the known highly conserved CXDXR and HXXC motifs were among them (data not shown). Homology modelling was performed according to multiple sequence alignment containing FC551456 (Ancylostoma caninum), F1LE18 (Ascaris suum), E5SH53 (Trichinella spiralis), and PDB 1EKJ by using the Modeller program (version 9.13) [57] with PDB model 1EKJ ( $\beta$-CA from Pisum sativum) as a template. A homology model for C4LXK3 (Entamoeba histolytica) was prepared using PDB 2A5V for pairwise alignment and as a template structure. The resulting models were structurally aligned using the BODIL program [58]. A figure illustrating the homology models was prepared by using the VMD program (version 1.9.1) [59], and edited within Adobe Photoshop (version 13.0.1).

The structural availability of the epitope in the PDB model 1EKJ ( $\beta$-CA from Pisum sativum) and the homology model based on the $\beta$-CA sequence from Ancylostoma caninum was studied by preparing the molecular surface with VMD, using a probe radius of $1.4 \AA$. The potential epitope residues were excluded from the surface presentation and were shown as Van der Waals (VdW) spheres.

\section{Results}

Multiple sequence alignment (MSA)

The MSA of 23 parasite and 8 plant $\beta$-CA sequences revealed the presence of the highly characteristic conserved sequence motifs CXDXR and HXXC (C: cysteine, $\mathrm{D}$ : aspartic acid, $\mathrm{R}$ : arginine, $\mathrm{H}$ : histidine, $\mathrm{X}$ : any residue) in all sequences. These results verify the presence of the $\beta$-CA enzyme in several insects and parasites which are pathogenic to various species of plants and animals and are thus considered relevant to agriculture and livestock husbandry (Figure 1).

\section{Phylogenetic analysis}

The results of the phylogenetic analysis of DNA sequences encoding 23 parasite and 8 plant $\beta$-CAs are shown in Figure 2. From the resulting tree we see four distinct clades, three of which represent distinct potential $\beta$-CA targets. From the top, the first clade represents $\beta$-CAs of invertebrate pests, the second clade are plant model organisms, the third clade is entirely represented by the four $\beta$-CAs of Ichthyophthirius multifiliis, and the final clade represents three species of amoeba. The Entamoeba spp. sequences occupy a midpoint between our outgroup bacteria species and the others.

\section{Prediction of subcellular localization}

The results of subcellular localization prediction of $\beta$-CAs in selected parasite and plant species are shown in Table 2. The predictions were based on the analysis of full-length $\beta$-CA protein sequences. In the Name column, there are both the UniProt ID and species scientific name. The results reveal that 6 of $23 \beta$-CAs from parasites (XP_004537221.1, B0WKV7, U6PDI1, E5SH53, B3S5Y1, and predicted BCA2 in A. pisum) were predicted to have a mitochondrial localization signal; 6 of $8 \beta$-CAs of plants (P17067, Q8LSC8, P27141, D7TWP2, I2FJZ8, and B9GHR1) were predicted to have a chloroplastic localization.

\section{Prediction of antigenic sites in $\beta$-CA}

According to the acceptable $3-85$ residue variation in epitope length of an antigen [60] and default parameters 


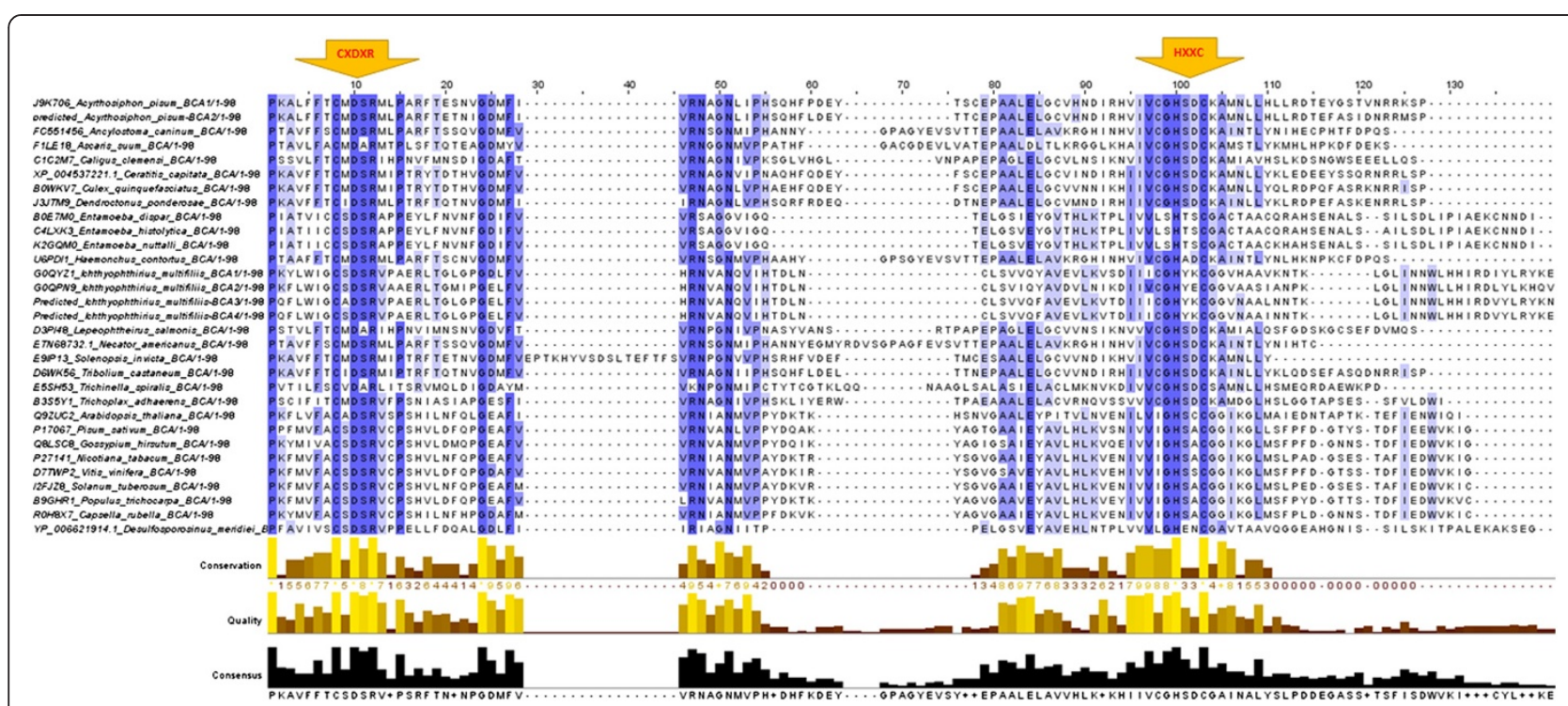

Figure 1 Multiple sequence alignment of 23 parasite, 8 plant, and one bacterial (Desulfosporosinus meridiei) $\beta$-CA sequences showing the most conserved region of the active site. The first (CXDXR) and second (HXXC) highly conserved sequences which are involved in zinc atom binding in catalytic active sites of the enzyme are marked with arrows at the top of the figure.

of EMBOSS Antigenic database, the minimum length of an antigenic region in this set of $\beta$-CAs is 6 amino acid residues. The predictions of antigenic sites in the $31 \beta$ CA proteins are shown in Table 3 ; the highest score belongs to the most antigenic site.

\section{Homology modelling}

Homology models of four selected $\beta$-CAs verified the predicted localization of conserved residues in the active site. Two loop regions showed high variability in the sequence length which is apparent in the Figure $3 \mathrm{C}, \mathrm{D}$ and indicated by “*” and “***". In addition, homology modelling suggested insertion located within the longest $\alpha$-helix in case of homology models based on $1 \mathrm{EKJ}$ (Figure 3C, indicated by “**:*).

To study the molecular availability of the predicted main antigenic epitope, surface exposure of the homology model created from PDB model 1EKJ ( $\beta$-CA from Pisum sativum) and the homology model based on the $\beta$-CA sequence from Ancylostoma caninum were studied

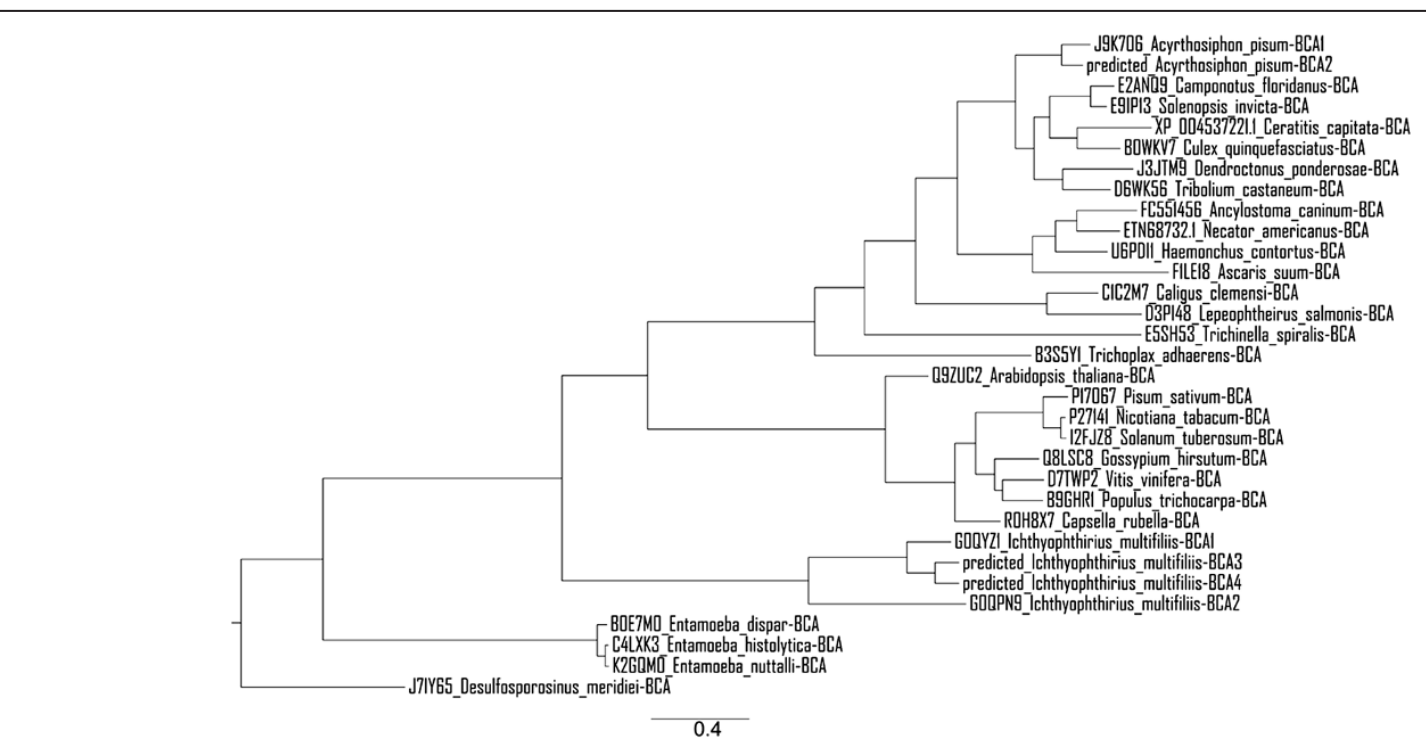

Figure 2 Phylogenetic analysis of $\beta$-CAs from 23 parasite and 8 plant species. $\beta$-CA from Desulfosporosinus meridiei was used as a bacterial outgroup. 
Table 2 Prediction of subcellular localization of 23 pest and 8 plant $\beta$-CAs

\begin{tabular}{|c|c|c|c|c|c|c|c|c|}
\hline Species name & Entry ID & $\beta-C A$ ID & cTP & mTP & SP & Other & RC & Loc \\
\hline Acyrthosiphon pisum & J9K706 & BCA1 & - & 0.473 & 0.050 & 0.631 & 5 & - \\
\hline Acyrthosiphon pisum & Predicted & BCA2 & - & 0.579 & 0.043 & 0.536 & 5 & M \\
\hline Ancylostoma caninum & FC551456 & $B C A$ & - & 0.466 & 0.046 & 0.514 & 5 & - \\
\hline Ascaris suum & F1LE18 & $B C A$ & - & 0.388 & 0.079 & 0.406 & 5 & - \\
\hline Caligus clemensi & $\mathrm{C} 1 \mathrm{C} 2 \mathrm{M} 7$ & $B C A$ & - & 0.210 & 0.040 & 0.873 & 2 & - \\
\hline Camponotus floridanus & E2ANQ9 & $B C A$ & - & 0.325 & 0.051 & 0.735 & 3 & - \\
\hline Ceratitis capitata & XP_004537221.1 & $B C A$ & - & 0.549 & 0.039 & 0.512 & 5 & M \\
\hline Culex quinquefasciatus & BOWKV7 & $\mathrm{BCA}$ & - & 0.573 & 0.032 & 0.507 & 5 & M \\
\hline Dendroctonus ponderosae & J3JTM9 & $B C A$ & - & 0.270 & 0.064 & 0.742 & 3 & - \\
\hline Entamoeba dispar & B0E7MO & $B C A$ & - & 0.114 & 0.158 & 0.766 & 2 & - \\
\hline Entamoeba histolytica & C4LXK3 & $B C A$ & - & 0.113 & 0.151 & 0.779 & 2 & - \\
\hline Entamoeba nuttalli & K2GQM0 & $\mathrm{BCA}$ & - & 0.132 & 0.142 & 0.763 & 2 & - \\
\hline Haemonchus contortus & U6PDI1 & $\mathrm{BCA}$ & - & 0.587 & 0.057 & 0.403 & 5 & M \\
\hline Ichthyophthirius multifiliis & G0QYZ1 & BCA1 & - & 0.071 & 0.046 & 0.946 & 1 & - \\
\hline Ichthyophthirius multifiliis & GOQPN9 & BCA2 & - & 0.181 & 0.040 & 0.872 & 2 & - \\
\hline Ichthyophthirius multifiliis & Predicted & $\mathrm{BCA3}$ & - & 0.059 & 0.078 & 0.954 & 1 & - \\
\hline Ichthyophthirius multifiliis & Predicted & BCA4 & - & 0.050 & 0.178 & 0.868 & 2 & - \\
\hline Lepeophtheirus salmonis & D3PI48 & $B C A$ & - & 0.126 & 0.068 & 0.889 & 2 & - \\
\hline Necator americanus & ETN68732.1 & $B C A$ & - & 0.379 & 0.036 & 0.604 & 4 & - \\
\hline Solenopsis invicta & E91P13 & $\mathrm{BCA}$ & - & 0.326 & 0.052 & 0.756 & 3 & - \\
\hline Tribolium castaneum & D6WK56 & $B C A$ & - & 0.054 & 0.097 & 0.938 & 1 & - \\
\hline Trichinella spiralis & E5SH53 & $B C A$ & - & 0.876 & 0.028 & 0.177 & 2 & M \\
\hline Trichoplax adhaerens & B3S5Y1 & $B C A$ & - & 0.582 & 0.038 & 0.459 & 5 & M \\
\hline Arabidopsis thaliana & Q9ZUC2 & $B C A$ & 0.043 & 0.171 & 0.108 & 0.923 & 2 & - \\
\hline Pisum sativum & P17067 & $\mathrm{BCA}$ & 0.969 & 0.050 & 0.014 & 0.023 & 1 & C \\
\hline Gossypium hirsutum & Q8LSC8 & $B C A$ & 0.947 & 0.154 & 0.008 & 0.019 & 2 & C \\
\hline Nicotiana tabacum & P27141 & $B C A$ & 0.956 & 0.059 & 0.019 & 0.039 & 1 & C \\
\hline Vitis vinifera & D7TWP2 & $B C A$ & 0.902 & 0.183 & 0.016 & 0.034 & 2 & C \\
\hline Solanum tuberosum & I2FJZ8 & $\mathrm{BCA}$ & 0.954 & 0.051 & 0.024 & 0.045 & 1 & C \\
\hline Populus trichocarpa & B9GHR1 & $B C A$ & 0.931 & 0.231 & 0.021 & 0.012 & 2 & C \\
\hline Capsella rubella & $\mathrm{ROH} 8 \times 7$ & $B C A$ & 0.040 & 0.208 & 0.176 & 0.907 & 2 & - \\
\hline
\end{tabular}

$C T P=$ a chloroplast transit peptide, $m T P=$ a mitochondrial targeting peptide, $S P=$ secretory pathway, $L o c$ (predicted localization) where $C=$ chloroplastic, $M=$ mitochondrial, $S=$ secretory, $-=$ other, $R C=$ reliability class, from 1 to 5 , where 1 indicates the strongest prediction. $R C$ is a measure of the difference between the highest and the second highest output scores. There are 5 reliability classes, defined as follows: $1:$ diff $\geq 0.800,2: 0.800>$ diff $\geq 0.600,3: 0.600>$ diff $\geq 0.400$, 4: $0.400>\operatorname{diff} \geq 0.200$ and 5: $0.200>$ diff. Thus, the lower the value of RC the safer the prediction.

by visualizing the molecular surface (Figure 4). The analysis revealed that the majority of the epitope was buried within the structure. The residues considered to be mainly buried in the structure are shown in green, while solvent-exposed residues are shown with red colour. Two residues in PDB model 1EKJ ( $\beta$-CA from Pisum sativum) appear considerably smaller than their complements in the Ancylostoma caninum-based homology model, and those residues can be considered to be only partially exposed (Figure 4, indicated by yellow colour in the alignment). Taken together, these results indicate that the predicted epitope sequence is mainly buried in $\beta$-CA sequences.

\section{Discussion}

Several insect, parasite, and plant genomes contain genes which encode $\beta$-CA enzymes. Some of these parasites and insects are either causative agents or vectors of important veterinary, fish farming, and zoonotic diseases (Table 1). For this analysis we selected $31 \beta$-CAs, 23 from parasites and 8 from plants. These sequences were retrieved from protein databases, or predicted from their genomes, 
Table 3 Predicted antigenic sites of 23 pest and 8 plant $\beta$-CA primary sequences

\begin{tabular}{|c|c|c|c|c|c|}
\hline Species name & Entry ID & $\beta$-CA ID & $\begin{array}{c}\text { Pest or } \\
\text { plant }\end{array}$ & HitCount ${ }^{*}$ & The most antigenic epitope \\
\hline Acyrthosiphon pisum & J9K706 & BCA1 & Pest & 14 & 77 YTSCEPAALELGCVHNDIRHVIVCGHSDC 105 \\
\hline Acyrthosiphon pisum & Predicted & BCA2 & Pest & 14 & 79 TCEPAALELGCVHNDIRHVIVCGHSDC 105 \\
\hline Ancylostoma caninum & FC551456 & $\mathrm{BCA}$ & Pest & 11 & 101 INHVIVCGHSDCKAINTLYNIHECPHTFDP 130 \\
\hline Ascaris suum & F1LE18 & $\mathrm{BCA}$ & Pest & 15 & 102 KHAIVCGHSDCKAMST 117 \\
\hline Caligus clemensi & C1C2M7 & $\mathrm{BCA}$ & Pest & 10 & 84 EPAGLELGCVLNSIKNVIVCGHSDCKAMIAVHSL 117 \\
\hline Camponotus floridanus & E2ANQ9 & $\mathrm{BCA}$ & Pest & 11 & 80 CESAALELGCWNDIRHVIVCGHSDC 105 \\
\hline Ceratitis capitata & XP_004537221.1 & $\mathrm{BCA}$ & Pest & 13 & 72 HFQDEYFSCEPAALELGCVINDIRHIIVCGHSD 104 \\
\hline Culex quinquefasciatus & BOWKV7 & $\mathrm{BCA}$ & Pest & 14 & 75 DEYFSCEPAALELGCWNNIKHIIVCGHSDC 105 \\
\hline Dendroctonus ponderosae & J3JTM9 & $\mathrm{BCA}$ & Pest & 13 & 95 RHIIVCGHSDCKAINLLYKL 114 \\
\hline Entamoeba dispar & BOE7MO & $\mathrm{BCA}$ & Pest & 8 & 85 SIEYGVTHLKTPLIVLSHTSCGACTAACQRA 116 \\
\hline Entamoeba histolytica & C4LXK3 & $\mathrm{BCA}$ & Pest & 8 & 83 LGSVEYGVTHLKTPLIWLSHTSCGACTAACQRA 116 \\
\hline Entamoeba nuttalli & K2GQM0 & $\mathrm{BCA}$ & Pest & 7 & 83 LGSVEYGVTHLKTPLIVLSHTSCGACTAACKHA 116 \\
\hline Haemonchus contortus & U6PDI1 & $\mathrm{BCA}$ & Pest & 13 & 101 HINHVIVCGHADCKAINTLYNL 122 \\
\hline Ichthyophthirius multifiliis & G0QYZ1 & BCA1 & Pest & 13 & 193 ANQVIHTDLNCLSWQYAVEVLKVSDIIICGHYKCGGVHAAVKNT 237 \\
\hline Ichthyophthirius multifiliis & G0QPN9 & $\mathrm{BCA} 2$ & Pest & 9 & 86 ANQVIHTDLNCLSVIQYAVDVLNIKDIIVCGHYECGGVAASIANPKLGL 134 \\
\hline Ichthyophthirius multifiliis & Predicted & BCA3 & Pest & 7 & 65 ANQVIHTDLNCLSWQFAVEVLKVTDIIICGHYKCGGVNAA 105 \\
\hline Ichthyophthirius multifiliis & Predicted & BCA4 & Pest & 6 & 62 ANQVIHTDLNCLSWQFAVEVLKVTDIIICGHYKCGGVNA 101 \\
\hline Lepeophtheirus salmonis & D3PI48 & BCA & Pest & 10 & 82 PEPAGLELGCWNSIKNWWCGHSDCKAMIALQSF 116 \\
\hline Necator americanus & ETN68732.1 & $\mathrm{BCA}$ & Pest & 10 & 108 HINHVIVCGHSDCKAINTLYNIHTCPQ 134 \\
\hline Solenopsis invicta & E9IP13 & $\mathrm{BCA}$ & Pest & 14 & 97 CESAALELGCWNDIKHVIVCGHSDC 122 \\
\hline Tribolium castaneum & D6WK56 & $\mathrm{BCA}$ & Pest & 13 & 116 ALELGCWNDIRHIIVCGHSDCKAINLLYKLQDS 149 \\
\hline Trichinella spiralis & E5SH53 & $\mathrm{BCA}$ & Pest & 11 & 100 KDIWCGHSDC 110 \\
\hline Trichoplax adhaerens & B3S5Y1 & $\mathrm{BCA}$ & Pest & 13 & 82 EAAALELACVRNQVSSWWCGHSDC 106 \\
\hline Arabidopsis thaliana & Q9ZUC2 & $\mathrm{BCA}$ & Plant & 13 & 80 PKFLVFACADSRVSPSHILNFQ 101 \\
\hline Pisum sativum & P17067 & $\mathrm{BCA}$ & Plant & 16 & 153 PFMVFACSDSRVCPSHVLDFQ 173 \\
\hline Gossypium hirsutum & Q8LSC8 & $\mathrm{BCA}$ & Plant & 14 & 151 KYMIVACSDSRVCPSHVLDM 170 \\
\hline Nicotiana tabacum & P27141 & $\mathrm{BCA}$ & Plant & 15 & 146 KFMVFACSDSRVCPSHVLNF 165 \\
\hline Vitis vinifera & D7TWP2 & $\mathrm{BCA}$ & Plant & 13 & 149 KFMVFACSDSRVCPSHVLDFQ 169 \\
\hline Solanum tuberosum & I2FJZ8 & $\mathrm{BCA}$ & Plant & 15 & 146 KFMVFACSDSR VCPSHVLNF 165 \\
\hline Populus trichocarpa & B9GHR1 & $\mathrm{BCA}$ & Plant & 13 & 146 KFMVFACSDSRVCPSHVLDFQ 166 \\
\hline Capsella rubella & $\mathrm{ROH} 8 \times 7$ & $\mathrm{BCA}$ & Plant & 11 & 84 KYMVFACSDSRVCPSHILNFH 104 \\
\hline
\end{tabular}

The italic and bolded residues represent the first (CXDXR) and second (HXXC) highly conserved sequences in the catalytic active sites of the enzyme whenever present in the predicted epitope.

*:HitCount means the total number of antigenic residues in the whole sequence of one protein or antigen.

and all selected host or vector species are considered important for agriculture or livestock husbandry, or represent model organisms. The most significant species included Ancylostoma caninum, Ascaris suum (Ascaris lumbricoides), Caligus clemensi, Culex quinquefasciatus, Entamoeba spp, Haemonchus contortus, Ichthyophthirius multifiliis, Lepeophtheirus salmonis, Necator americanus, Trichinella spiralis, and Trichoplax adhaerens. One was an important pest in food industries (Tribolium castaneum). There was also an orchard invasive dipteran fruit fly (Ceratitis capitata) and three pests of wood industries, such as Camponotus floridanus, Dendroctonus ponderosae, and Solenopsis invicta.

Our MSA of $\beta$-CAs in plants, parasites, and insects showed that they all contain the first (CXDXR) and second (HXXC) highly conserved sequences of $\beta$-CA. The presence of $\beta$-CA proteins in various insects and parasites and their absence in mammals suggests that these enzymes could be potential targets for the development of novel pesticides or anti-parasitic drugs with minimal side effects on vertebrates. A key requirement for such novel $\beta$-CA inhibitors is the high isoform specificity. The 

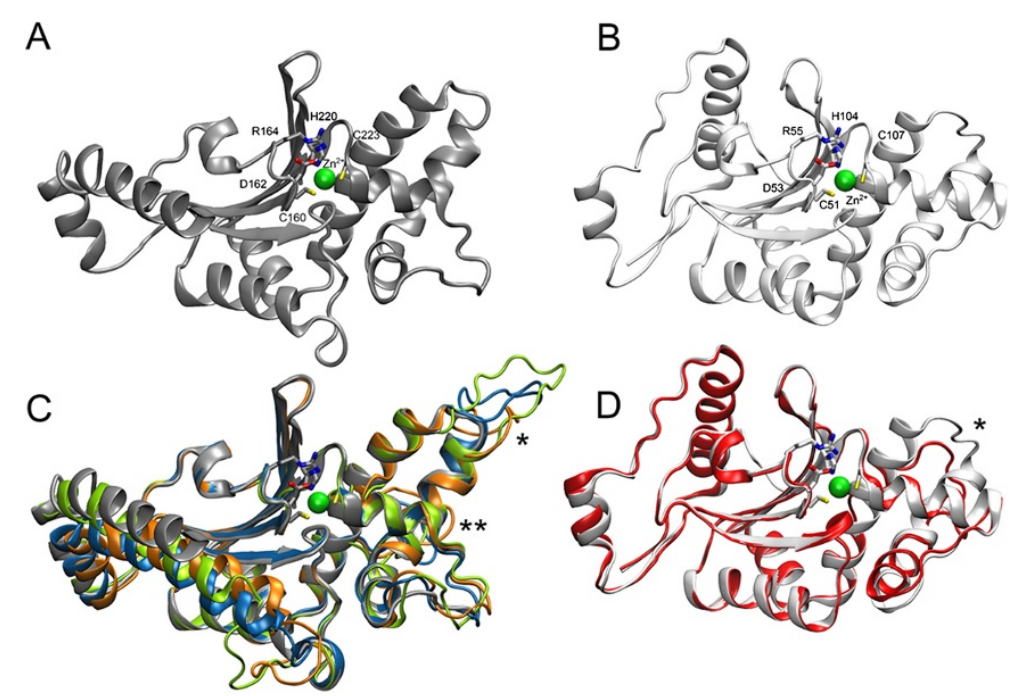

Figure 3 Homology modelling. (A) Cartoon presentation of $\beta$-CA from Pisum sativum (PDB 1EKJ). The $\mathrm{Zn}^{2+}$ ion is shown as green sphere and the residues in direct contact with the ion are shown as liquorice models and labeled with residue numbers. (B) $\beta$-CA from Mycobacterium tuberculosis (PDB 2A5V, light gray). (C) Aligned homology models of $\beta$-CAs from Ancylostoma caninum (green), Ascaris suum (blue), and Trichinella spiralis (orange) are shown with PDB 1EKJ (gray). (D) Homology model of and Entamoeba histolytica (red) structurally aligned with PDB 2A5V (light gray). Highly variable loop regions are indicated by stars ("*" and "**") (C, D). Insertion suggested by homology models of Ancylostoma caninum, Ascaris suum and Trichinella spiralis is indicated by three stars (C). The figure was prepared by using VMD (version 1.9.1).

distinction among $\beta$-CA proteins elucidated in the phylogenetic tree indicates that inhibitors can be created which would target $\beta$-CAs specific to different groups of species, leaving those in other species, such as plants, unaffected. Unfortunately, design of highly specific inhibitors will require proper structural data based on protein crystallography. Thus far, $\beta$-CA crystal structures from only a few different species are available in PDB database (http:// www.rcsb.org/pdb/home/home.do), including some algae, bacteria, archaea, yeast, and a plant Pisum sativum [61].
Our prediction results on the subcellular localization of $\beta$-CAs showed that 6 of $23 \beta$-CAs from parasites (XP_004537221.1, B0WKV7, U6PDI1, E5SH53, B3S5Y1, and predicted $\mathrm{BCA} 2$ in A. pisum) are probably mitochondrial enzymes. It is well known that several pesticides have unwanted side effects because of their off-target impacts on mitochondria [62]. Blocking of $\beta$-CAs in insect and parasitic cells can affect mitochondrial metabolic cycles and possibly eradicate the pathogens. Figure 5 presents 14 categories of known $\alpha$ - and/or $\beta$-CA inhibitors, which

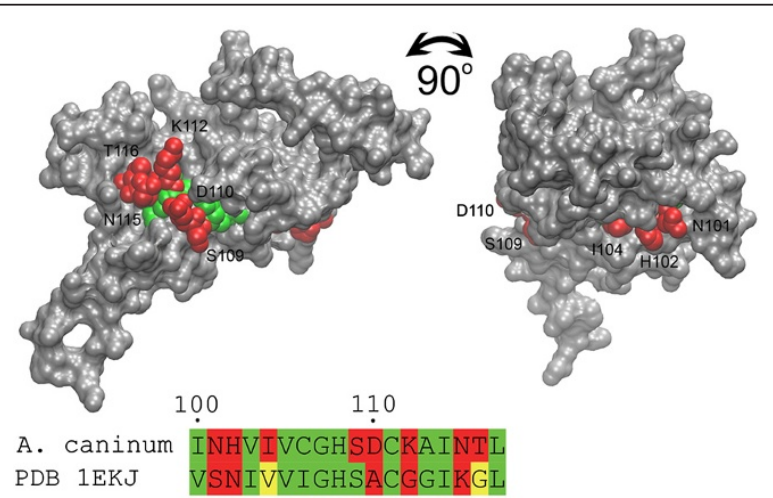

Figure 4 Determination of the availability of the predicted epitope. The molecular surface of the homology model of $\beta$-CA from Ancylostoma caninum is shown as solid grey and the target epitope sequence was excluded from the surface presentation. The epitope residues exposed to solvent are shown as red VdW spheres and numbered, while buried residues are shown with green spheres. An alignment containing PDB 1EKJ and the corresponding sequence from Ancylostoma caninum predicted $\beta-C A$ is shown. The numbering of the residues in the alignment is according to the Ancylostoma caninum sequence. The yellow residues in the alignment indicate partially buried structure. 


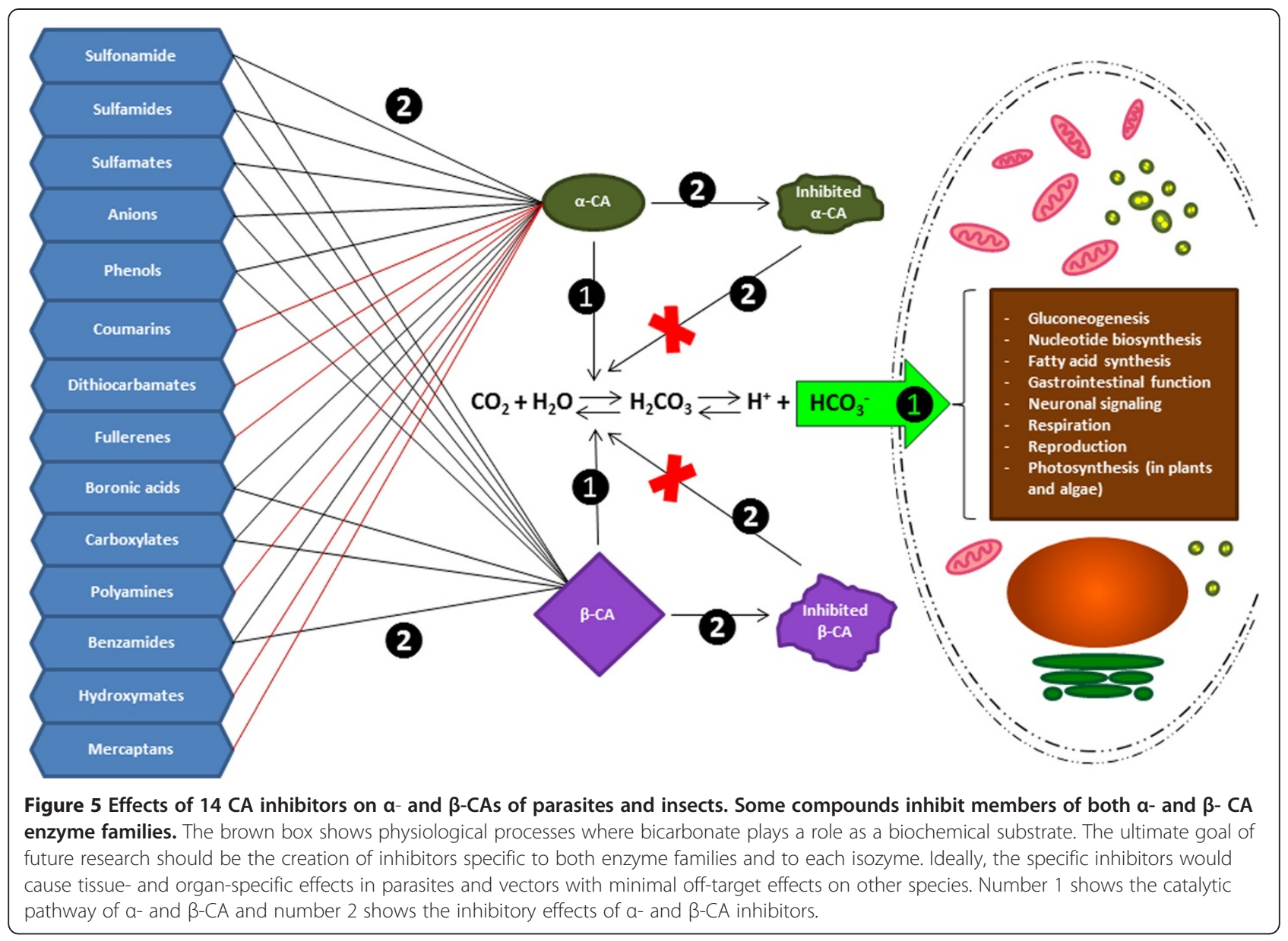

are able to inhibit catalytic activity of these enzyme families $[63,64]$. As the result, inhibition of CA activity would slow down some cellular biochemical pathways in parasites and insects, such as gluconeogenesis, nucleotide biosynthesis, fatty acid synthesis, gastrointestinal function, neuronal signaling, respiration, and reproduction. In plants and algae, it is known that $\beta$-CAs are required for $\mathrm{CO}_{2}$ sequestration within chloroplast, and therefore CA inhibition would affect the rate of photosynthesis [65]. Importantly, $\beta$-CA inhibition in fungi and Drosophila melanogaster revealed completely different inhibition profiles [17], suggesting that $\beta$-CAs of parasites and insects can be inhibited with higher affinity than plant CAs by applying the right inhibitors and concentrations.

Another important goal is to find inhibitors that are specific for $\beta$-CAs and do not affect $\alpha$-CAs at all. This would first require detailed structural data on selected parasite and insect CAs. The resolved structures would then allow high throughput screening of chemical compounds, identification of the most promising inhibitor molecules, and testing of potential compounds in vitro and in vivo.
Vaccination would offer another option to develop antiparasitic treatments based on $\beta$-CAs. In our study we used computational antigen prediction tools, which have been developed to reduce the laboratory work required to identify important antigenic epitopes in pathogenic proteins [66]. The Protegen database (http://www.violinet.org/ protegen/) has been used to identify a number of predicted antigens from bacteria, viruses, parasites and fungi, which are involved in immune responses against various infectious and non-infectious diseases [67]. Antigenic site prediction of $\beta$-CA of parasites and plants revealed that the first and second highly conserved sequences (CXDXR and HXXC) represent the most plausible antigenic sites of $\beta$-CAs. Because these epitopes are located in the region of the active site and are mainly buried (Figure 4), they show very limited promise as vaccine targets. Furthermore, most $\beta$-CAs are intracellular proteins which are not readily accessible for immunological recognition. Taking all of these results together, small molecule inhibitors should still be considered the first option when $\beta$-CAs are investigated as therapeutic target proteins. 


\section{Conclusions}

Our present work is the first study that discusses the potential role of $\beta$-CAs as target proteins for pesticides and anti-parasitic agents in agriculture and livestock husbandry. Our results could potentially have significant impacts on development of novel pesticides, which would directly benefit both food and forest industries. This is important as pests cause significant costs for agricultural, horticultural, and livestock husbandry products due to production losses [68]. Since $\beta$-CA sequences are not present in the genomes of vertebrates, the possible offtarget effects in human and vertebrate animals should be minimal if high isozyme specificity is achieved. Discovery and validation of a new generation of $\beta$-CA inhibitors as pesticides and anti-parasitic agents would be a novel research field for chemical and pharmaceutical industries to improve safe nutrition and general health in societies.

\section{Competing interests}

The authors declare that they have no competing interests.

\section{Authors' contributions}

All authors participated in the design of the study. RZE carried out the bioinformatics searches on parasites and plant species. RZE and HB participated in the sequence alignment. HB made protein sequence corrections and predictions and performed the phylogenetic analysis. RZE performed the mitochondrial targeting peptide and antigenic site prediction. RZE and VH participated in the homology modelling. RZE, HB and VH drafted the first version of the manuscript. All authors participated in writing further versions and read and approved the final manuscript.

\section{Acknowledgment}

To perform these studies RZE received a scholarship support from the Ministry of Science, Research and Technology, and National Institute of Genetic Engineering and Biotechnology of Islamic Republic of Iran. This study was also funded by Finnish Cultural Foundation (HB), Sigrid Juselius Foundation (SP), Jane and Aatos Erkko Foundation (SP), Academy of Finland $(\mathrm{VH})$ and Competitive Research Funding of the Tampere University Hospital $(\mathrm{SP}, \mathrm{VH})$.

\section{Author details}

'School of Medicine, University of Tampere, 33520 Tampere, Finland. ${ }^{2}$ BioMediTech, University of Tampere, 33520 Tampere, Finland. ${ }^{3}$ Fimlab Laboratories Ltd and Tampere University Hospital, Biokatu 4, 33520 Tampere, Finland. ${ }^{4}$ Department of Information Technology, University of Turku, 20014 Turku, Finland.

Received: 21 May 2014 Accepted: 20 August 2014 Published: 29 August 2014

\section{References}

1. Zalucki MP, Shabbir A, Silva R, Adamson D, Shu-Sheng L, Furlong MJ: Estimating the economic cost of one of the world's major insect pests, Plutella xylostella (Lepidoptera: Plutellidae): just how long is a piece of string? J Econ Entomol 2012, 105(4):1115-1129.

2. Way MJ: Crop losses by insects and the problem of control. Proc Nutr Soc 1961, 20:5-11.

3. Aktar MW, Sengupta D, Chowdhury A: Impact of pesticides use in agriculture: their benefits and hazards. Interdiscip Toxicol 2009, 2(1):1-12.

4. Rakotondravelo ML, Anderson TD, Charlton RE, Zhu KY: Sublethal effects of three pesticides on activities of selected target and detoxification enzymes in the aquatic midge, Chironomus tentans (diptera: chironomidae). Archiv Environ Contam Toxicol 2006, 51(3):360-366

5. Ayvaz A, Sagdic O, Karaborklu S, Ozturk I: Insecticidal activity of the essential oils from different plants against three stored-product insects. J Insect Sci 2010, 10:21.
6. Chandler D, Bailey AS, Tatchell GM, Davidson G, Greaves J, Grant WP: The development, regulation and use of biopesticides for integrated pest management. Philos Trans R Soc Lond B Biol Sci 2011, 366(1573):1987-1998. 7. Sudakin DL: Biopesticides. Toxicol Rev 2003, 22(2):83-90.

8. Glare T, Caradus J, Gelernter W, Jackson T, Keyhani N, Kohl J, Marrone P, Morin L, Stewart A: Have biopesticides come of age? Trends Biotechnol 2012, 30(5):250-258.

9. Pang YP: Novel acetylcholinesterase target site for malaria mosquito control. PLoS One 2006, 1:e58.

10. Haq SK, Atif SM, Khan RH: Protein proteinase inhibitor genes in combat against insects, pests, and pathogens: natural and engineered phytoprotection. Arch Biochem Biophys 2004, 431(1):145-159.

11. Wu G, Miyata T, Kang CY, Xie LH: Insecticide toxicity and synergism by enzyme inhibitors in 18 species of pest insect and natural enemies in crucifer vegetable crops. Pest Manag Sci 2007, 63(5):500-510.

12. Krungkrai SR, Krungkrai J: Malaria parasite carbonic anhydrase: inhibition of aromatic/heterocyclic sulfonamides and its therapeutic potential. Asian Pac J Trop Biomed 2011, 1(3):233-242.

13. Crocetti L, Maresca A, Temperini C, Hall RA, Scozzafava A, Muhlschlegel FA Supuran CT: A thiabendazole sulfonamide shows potent inhibitory activity against mammalian and nematode alpha-carbonic anhydrases. Bioorg Med Chem Lett 2009, 19(5):1371-1375.

14. Kumar RS, Ferry JG: Prokaryotic carbonic anhydrases of Earth's environment. Subcell Biochem 2014, 75:77-87.

15. Alterio V, Vitale RM, Monti SM, Pedone C, Scozzafava A, Cecchi A, De Simone G, Supuran CT: Carbonic anhydrase inhibitors: X-ray and molecular modeling study for the interaction of a fluorescent antitumor sulfonamide with isozyme II and IX. J Am Chem Soc 2006, 128(25):8329-8335.

16. Rowlett RS: Structure and catalytic mechanism of the beta-carbonic anhydrases. Biochim Biophys Acta 2010, 1804(2):362-373.

17. Syrjanen $L$, Tolvanen M, Hilvo M, Olatubosun A, Innocenti A, Scozzafava A, Leppiniemi J, Niederhauser B, Hytonen VP, Gorr TA, Parkkila S, Supuran CT: Characterization of the first beta-class carbonic anhydrase from an arthropod (Drosophila melanogaster) and phylogenetic analysis of beta-class carbonic anhydrases in invertebrates. BMC Biochem 2010, 11:28.

18. Zolfaghari Emameh $\mathrm{R}$, Barker $\mathrm{H}$, Tolvanen ME, Ortutay C, Parkkila S: Bioinformatic analysis of beta carbonic anhydrase sequences from protozoans and metazoans. Parasit Vectors 2014, 7(1):38.

19. Tobal JM, Balieiro ME: Role of carbonic anhydrases in pathogenic micro-organisms: a focus on Aspergillus fumigatus. J Med Microbio/ 2014 63(Pt 1):15-27.

20. Sievers F, Wilm A, Dineen D, Gibson TJ, Karplus K, Li W, Lopez R, McWilliam $H$, Remmert M, Soding J, Thompson JD, Higgins DG: Fast, scalable generation of high-quality protein multiple sequence alignments using Clustal Omega. Mol Syst Biol 2011, 7:539.

21. Waterhouse AM, Procter JB, Martin DM, Clamp M, Barton GJ: Jalview Version 2-a multiple sequence alignment editor and analysis workbench. Bioinformatics 2009, 25(9):1189-1191.

22. Stavrinides J, McCloskey JK, Ochman H: Pea aphid as both host and vector for the phytopathogenic bacterium Pseudomonas syringae. Appl Environ Microbiol 2009, 75(7):2230-2235.

23. Prociv $P$, Croese J: Human enteric infection with Ancylostoma caninum: hookworms reappraised in the light of a "new" zoonosis. Acta Trop 1996, 62(1):23-44.

24. Leles D, Gardner SL, Reinhard K, Iniguez A, Araujo A: Are Ascaris lumbricoides and Ascaris suum a single species? Parasit Vectors 2012 5:42.

25. Jones SR, Prosperi-Porta G, Kim E, Callow P, Hargreaves NB: The occurrence of Lepeophtheirus salmonis and Caligus clemensi (Copepoda: Caligidae) on three-spine stickleback Gasterosteus aculeatus in coastal British Columbia. J Parasitol 2006, 92(3):473-480.

26. Kafil M, Bandani AR, Kaltenpoth M, Goldansaz SH, Alavi SM: Role of Symbiotic Bacteria in the Growth and Development of the Sunn Pest, Eurygaster integriceps. J Insect Sci 2013, 13:99.

27. Tabilio MR, Fiorini D, Marcantoni E, Materazzi S, Delfini M, De Salvador FR, Musmeci S: Impact of the Mediterranean fruit fly (medfly) Ceratitis capitata on different peach cultivars: the possible role of peach volatile compounds. Food Chem 2013, 140(1-2):375-381.

28. Linthicum KJ: Introduction to the symposium Global Perspective on the Culex pipiens Complex in the 21st century: The Interrelationship of 
Culex pipiens, quinquefasciatus, molestus and others. J Am Mosq Control Assoc 2012, 28(4 Suppl):4-9.

29. Knapp PA, Soule PT, Maxwell JT: Mountain pine beetle selectivity in old-growth ponderosa pine forests, Montana, USA. Ecol Evol 2013, 3(5):1141-1148.

30. Feng $M$, Yang B, Yang $L$, Fu $Y$, Zhuang $Y$, Liang $L$, Xu Q, Cheng $X$, Tachibana $\mathrm{H}$ : High prevalence of Entamoeba infections in captive long-tailed macaques in China. Parasitol Res 2011, 109(4):1093-1097.

31. Peter JW, Chandrawathani P: Haemonchus contortus: parasite problem No. 1 from tropics - Polar Circle. Problems and prospects for control based on epidemiology. Trop Biomed 2005, 22(2):131-137.

32. Buchmann K, Sigh J, Nielsen CV, Dalgaard M: Host responses against the fish parasitizing ciliate Ichthyophthirius multifiliis. Vet Parasitol 2001, 100(1-2):105-116.

33. Schneider B, Jariwala AR, Periago MV, Gazzinelli MF, Bose SN, Hotez PJ, Diemert DJ, Bethony JM: A history of hookworm vaccine development. Hum Vaccin 2011, 7(11):1234-1244.

34. Sun $\mathrm{Q}$, Zhou X: Corpse management in social insects. Int J Biol SCi 2013, 9(3):313-321.

35. Toews MD, Campbell JF, Arthur FH: The presence of flour affects the efficacy of aerosolized insecticides used to treat the red flour beetle, Tribolium castaneum. J Insect Sci 2010, 10:196.

36. Lis LB, Bakula T, Baranowski M, Czarnewicz A: The carcinogenic effects of benzoquinones produced by the flour beetle. Pol J Vet Sci 2011, 14(1):159-164

37. El-Mofty MM, Osman SI, Sakr SA, Toulan BA: Carcinogenicity of flour infested with Tribolium castaneum using the Egyptian toad Bufo regularis as a biological test animal. Oncology 1988, 45(1):65-67.

38. Alanko K, Tuomi T, Vanhanen M, Pajari-Backas M, Kanerva L, Havu K, Saarinen K, Bruynzeel DP: Occupational IgE-mediated allergy to Tribolium confusum (confused flour beetle). Allergy 2000, 55(9):879-882.

39. Gottstein B, Pozio E, Nockler K: Epidemiology, diagnosis, treatment, and control of trichinellosis. Clin Microbiol Rev 2009, 22(1):127-145. Table of Contents.

40. Schierwater B: My favorite animal, Trichoplax adhaerens. Bioessays 2005, 27(12):1294-1302

41. Theologis A, Ecker JR, Palm CJ, Federspiel NA, Kaul S, White O, Alonso J, Altafi H, Araujo R, Bowman CL, Brooks SY, Buehler E, Chan A, Chao Q, Chen $H$, Cheuk RF, Chin CW, Chung MK, Conn L, Conway AB, Conway AR, Creasy TH, Dewar K, Dunn P, Etgu P, Feldblyum TV, Feng J, Fong B, Fujii CY, Gill JE, et al: Sequence and analysis of chromosome 1 of the plant Arabidopsis thaliana. Nature 2000, 408(6814):816-820.

42. Majeau N, Coleman JR: Isolation and characterization of a CDNA coding for pea chloroplastic carbonic anhydrase. Plant Physiol 1991, 95(1):264-268.

43. Hoang CV, Wessler HG, Local A, Turley RB, Benjamin RC, Chapman KD: Identification and expression of cotton (Gossypium hirsutum L.) plastidial carbonic anhydrase. Plant Cell Physiol 1999, 40(12):1262-1270.

44. Majeau N, Arnoldo MA, Coleman JR: Modification of carbonic anhydrase activity by antisense and over-expression constructs in transgenic tobacco. Plant Mol Biol 1994, 25(3):377-385.

45. Jaillon O, Aury JM, Noel B, Policriti A, Clepet C, Casagrande A, Choisne N, Aubourg S, Vitulo N, Jubin C, Vezzi A, Legeai F, Huqueney P, Dasilva C, Horner D, Mica E, Jublot D, Poulain J, Bruyère C, Billault A, Segurens B, Gouyvenoux M, Ugarte E, Cattonaro F, Anthouard V, Vico V, Del Fabbro C, Alaux M, Di Gaspero G, Dumas V, et al: The grapevine genome sequence suggests ancestral hexaploidization in major angiosperm phyla. Nature 2007, 449(7161):463-467.

46. Rumeau D, Cuine S, Fina L, Gault N, Nicole M, Peltier G: Subcellular distribution of carbonic anhydrase in Solanum tuberosum L. leaves: characterization of two compartment-specific isoforms. Planta 1996, 199(1):79-88.

47. Tuskan GA, Difazio S, Jansson S, Bohlmann J, Grigoriev I, Hellsten U, Putnam N, Ralph S, Rombauts S, Salamov A, Schein J, Sterck L, Aerts A, Bhalerao RR, Bhalerao RP, Blaudez D, Boerjan W, Brun A, Brunner A, Busov V, Campbell M, Carlson J, Chalot M, Chapman J, Chen GL, Cooper D, Coutinho PM, Couturier J, Covert S, Cronk Q, et al: The genome of black cottonwood, Populus trichocarpa (Torr. \& Gray). Science 2006, 313(5793):1596-1604.

48. Moyroud E, Minguet EG, Ott F, Yant L, Pose D, Monniaux M, Blanchet S, Bastien O, Thevenon E, Weigel D, Schmid M, Parcy F: Prediction of regulatory interactions from genome sequences using a biophysical model for the Arabidopsis LEAFY transcription factor. Plant Cell 2011, 23(4):1293-1306.

49. Slater GS, Birney E: Automated generation of heuristics for biological sequence comparison. BMC Bioinform 2005, 6:31.

50. Suyama M, Torrents D, Bork P: PAL2NAL: robust conversion of protein sequence alignments into the corresponding codon alignments. Nucleic Acids Res 2006, 34:W609-W612. Web Server issue.

51. Ronquist F, Teslenko M, van der Mark P, Ayres DL, Darling A, Hohna S, Larget B, Liu L, Suchard MA, Huelsenbeck JP: MrBayes 3.2: efficient Bayesian phylogenetic inference and model choice across a large model space. Syst Biol 2012, 61(3):539-542.

52. Emanuelsson $\mathrm{O}$, Nielsen $\mathrm{H}$, Brunak S, von Heijne G: Predicting subcellular localization of proteins based on their $\mathrm{N}$-terminal amino acid sequence. J Mol Biol 2000, 300(4):1005-1016.

53. Kolaskar AS, Tongaonkar PC: A semi-empirical method for prediction of antigenic determinants on protein antigens. FEBS Lett 1990, 276(1-2):172-174

54. Rice P, Longden I, Bleasby A: EMBOSS: the European Molecular Biology Open Software Suite. Trends Genet 2000, 16(6):276-277.

55. Olson SA: EMBOSS opens up sequence analysis. European Molecular Biology Open Software Suite. Brief Bioinform 2002, 3(1):87-91.

56. Mullan LJ, Bleasby AJ: Short EMBOSS User Guide. European Molecular Biology Open Software Suite. Brief Bioinform 2002, 3(1):92-94.

57. Eswar N, Webb B, Marti-Renom MA, Madhusudhan MS, Eramian D, Shen MY, Pieper U, Sali A: Comparative protein structure modeling using Modeller. In Curr Protoc Bioinformatics. Edited by Baxevanis AD. Hoboken, NJ: John Wiley and Sons, Inc; 2006. Chapter 5:Unit 56

58. Lehtonen JV, Still DJ, Rantanen W, Ekholm J, Bjorklund D, Iftikhar Z, Huhtala M, Repo S, Jussila A, Jaakkola J, Pentikäinen O, Nyrönen T, Salminen T, Gyllenberg M, Johnson MS: BODIL: a molecular modeling environment for structure-function analysis and drug design. J Comput Aided Mol Des 2004, 18(6):401-419.

59. Humphrey W, Dalke A, Schulten K: VMD: visual molecular dynamics. J Mol Graph 1996, 14(1):33-38. 27-38

60. Singh H, Ansari HR, Raghava GP: Improved method for linear B-cell epitope prediction using antigen's primary sequence. PLOS One 2013, 8(5):e62216.

61. Kimber MS, Coleman JR, Pai EF: Beta-carbonic anhydrase from Pisum sativum: crystallization and preliminary X-ray analysis. Acta Crystallogr D Biol Crystallogr 2000, 56(Pt 7):927-929.

62. Yamano T, Morita S: Effects of pesticides on isolated rat hepatocytes, mitochondria, and microsomes II. Arch Environ Contam Toxicol 1995, 28(1):1-7.

63. Supuran CT: Carbonic anhydrase inhibition/activation: trip of a scientist around the world in the search of novel chemotypes and drug targets. Curr Pharm Des 2010, 16(29):3233-3245.

64. McKenna R, Supuran CT: Carbonic anhydrase inhibitors drug design. Subcell Biochem 2014, 75:291-323.

65. Badger $\mathrm{M}$ : The roles of carbonic anhydrases in photosynthetic $\mathrm{CO}_{2}$ concentrating mechanisms. Photosynth Res 2003, 77(2-3):83-94.

66. Flower DR, Macdonald IK, Ramakrishnan K, Davies MN, Doytchinova IA: Computer aided selection of candidate vaccine antigens. Immunome Res 2010, 6(Suppl 2):S1.

67. Yang B, Sayers S, Xiang Z, He Y: Protegen: a web-based protective antigen database and analysis system. Nucleic Acids Res 2011, 39(Database issue): D1073-D1078.

68. Gustafson DJ: Rising food costs \& global food security: key issues \& relevance for India. Indian J Med Res 2013, 138(3):398-410.

doi:10.1186/1756-3305-7-403

Cite this article as: Zolfaghari Emameh et al:: Beta carbonic anhydrases: novel targets for pesticides and anti-parasitic agents in agriculture and livestock husbandry. Parasites \& Vectors 2014 7:403. 